\title{
Performing and analyzing high-resolution anorectal
}

\section{manometry}

Eula Plana Tetangco, Yun Yan and Satish S.C. Rao

Neurogastroenterology/Motility, Digestive Health Clinical Research Center, Medical College of Georgia, Augusta University, Augusta, GA, USA

\section{RESUMEN}

Los desórdenes anorrectales afectan al 20\% de la población. Los trastornos comunes incluyen la incontinencia fecal, el dolor anorrectal funcional, la defecación disinérgica y otros trastornos de la defecación funcional. La manometría anorrectal, especialmente en la última década, ha surgido como una herramienta valiosa para la evaluación y el diagnóstico de estas afecciones. En esta revisión describimos nuestro enfoque para realizar un estudio meticuloso y de alta calidad, así como cumplir con los estándares mínimos para el procedimiento. Asimismo, describimos: instrucciones de preparación; composición del equipo, que incluye sonda, hardware y software; detalles técnicos del procedimiento, incluyendo varias maniobras; un análisis sistemático de los datos obtenidos mediante manometría anorrectal de alta resolución y, finalmente, cómo interpretar y generar un informe estándar. (NeuroGastroLatam Rev. 2018;2:120-132)

Corresponding author: Satish S.C. Rao, srao@augusta.edu

Palabras clave: Anorrectal. Manometría. Disinergia. Defecación. Estreñimiento. Incontinencia fecal.

\section{Correspondence to:}

Satish S.C. Rao, MD, PhD

Neurogastroenterology/Motility

Digestive Health Clinical Research Center

Medical College of Georgia, Augusta University

Augusta, GA, USA

E-mail:srao@augusta.edu

Received in original form: 13-10-2018

Accepted in final form: 10-01-2019

DOI: 10.24875/NGL.19000016 


\section{ABSTRACT}

Anorectal disorders affect $20 \%$ of the population. Common disorders include fecal incontinence, functional anorectal pain, dyssynergic defecation, and other functional defecation disorders. Anorectal manometry (ARM), especially over the past decade, has emerged as a valuable tool for the evaluation and diagnosis of these conditions. In this review, we describe our approach for performing a meticulous and high-quality study as well as adhering to minimum standards for the procedure. We describe preparation instructions to the subject; the equipment including probe, hardware, and software; technical details of the procedure including various maneuvers followed by a systematic analysis of the data obtained using high-resolution ARM, and finally, how to interpret and generate a standard report.

Key words: Anorectal. Manometry. Dyssynergic defecation. Constipation. Fecal incontinence.

\section{INTRODUCTION}

Anorectal manometry (ARM) is now accepted as a standard and valuable test by gastroenterologists and colorectal surgeons for the diagnosis and evaluation of defecatory disorders that affect over $20 \%$ of the population ${ }^{1}$. The indications for ARM include constipation, fecal incontinence, functional anorectal pain, rectal prolapse, pre- and post-pouch surgery, and functional defecatory disorders. Furthermore, it guides the approach for biofeedback therapy (neuromuscular training), particularly for subjects with dyssynergic defecation or fecal incontinence ${ }^{2}$. ARM is an important component of assessing anorectal disorders, and it complements other tests of morphological and functional anal physiology such as barium or magnetic resonance defecography, anal ultrasound, balloon expulsion test (BET), and translumbosacral anorectal magnetic stimulation test ${ }^{3}$. In this article, we review our approach for performing the procedure, including preparation of the subject, equipment, pre-procedure assessment, techniques and methods for performing high-resolution ARM, post-procedure assessments, data analysis, and interpretation of results.

\section{PRE-PROCEDURE ASSESSMENT}

\section{Clinic subject preparation}

The test takes approximately $1 \mathrm{~h}$. Before the procedure, the subject is instructed not to take any muscle relaxants or anticholinergic medications. Any stool softeners, laxatives, or enemas that the subject usually takes are permitted. An enema may be administered the night before or up to $2 \mathrm{~h}$ before the procedure.

On the day of the procedure, the subject is permitted to eat or drink as usual, unless other tests are scheduled. On arrival to the motility laboratory, the subject is asked to 


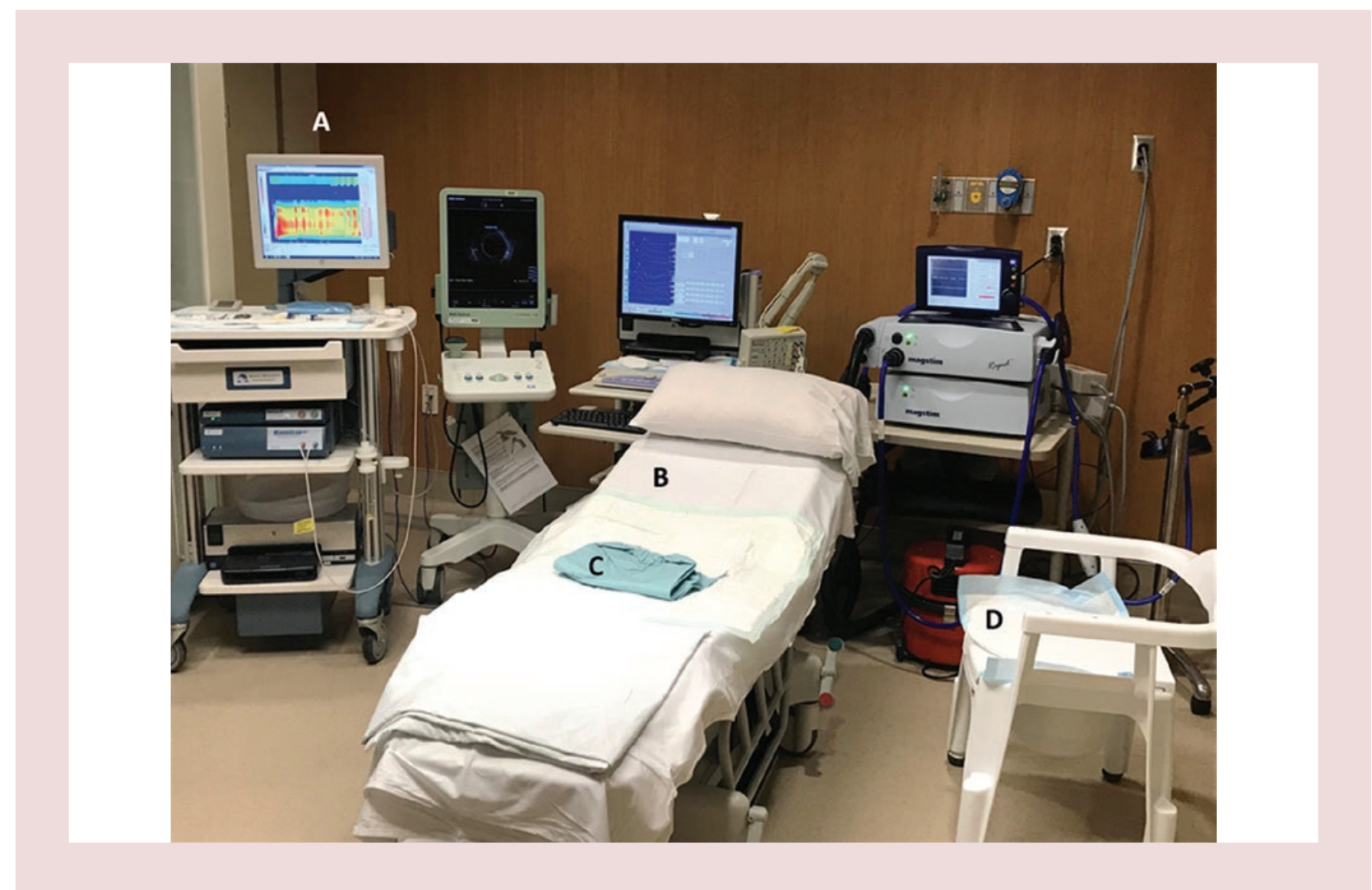

FiguRE 1. Motility laboratory set up for anorectal manometry showing (A) the ManoScan ${ }^{\mathrm{TM}}$ (Medtronic, Given Imaging, Minneapolis, MN) High-Resolution Manometry System, (B) examining table, (C) moon pants, and (D) commode.

change into a hospital gown and special underwear (moon pants), which are disposable shorts with a flap that can be opened to facilitate the procedure (Fig. 1). A nurse reviews the procedure with the subject, takes a brief health history, and answers any questions. Verbal or written informed consent is obtained according to regional policies. The subject is informed about the objectives of ARM, mainly to assess: (1) the strength of the anal muscles, (2) the rectal sensation, (3) the ability to have a bowel movement, (4) the ability to squeeze and hold a volume of fluid, and (5) the nerve supply to the anal muscle. It is explained that a catheter about the size of a pencil will be inserted approximately 6 inches into the rectum.

\section{Equipment}

ARM can be performed using conventional water-perfused or solid-state manometry probes with three to six unidirectional sensors. However, since 2007, these have been supplanted by higher fidelity, solid-state high-resolution probes. These probes have a greater number of circumferentially arranged sensors located at close intervals 4 . The high-resolution anorectal manometry (HRAM) is a flexible, $0.5 \mathrm{~cm}$ in diameter probe that is equipped with 12 circumferential sensors, 10 sensors at $6 \mathrm{~mm}$ intervals along the anal canal, and another 2 sensors inside a rectal balloon (Fig. 2). The 3D high-definition ARM probe is a rigid probe. It can create anorectal 


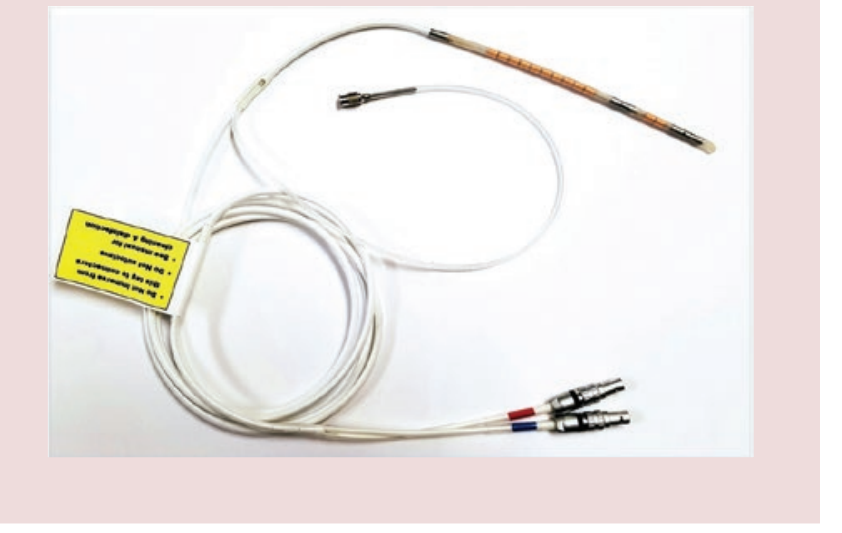

Figure 2. High-resolution anorectal manometry probe.

3D pressure models that can reveal dynamic changes in anatomy during simulated defecation. This paper will focus on HRAM. HRAM is susceptible to "thermal drift", changes in pressure due to changes in environmental and body temperature, that requires careful calibration". During analysis, a "thermal compensation" algorithm within the software can correct this phenomenon. The enhanced resolution from these catheters allows for more heightened scrutiny of anorectal disorders and diagnostic advancements. The main disadvantages are shorter lifespan (guaranteed for 200 uses) and expense ${ }^{5}$.

\section{Patient positioning}

The subject, dressed in a gown and moon pants, is asked to lie on the examining table in the left lateral position with knees bent. If required, a small cushion is placed between the knees. The perianal region is inspected for fissures, fistulae, scars, skin tags, and hemorrhoids. Next, a careful digital rectal examination (DRE) is performed by introducing a gloved and lubricated right index finger into the rectum. DRE should be performed in all subjects before ARM, both to facilitate catheter insertion and obtain information on anorectal anatomy. In addition, evaluating the push effort during DRE is reliable in identifying dyssynergia and guides subsequent physiologic testing. Dyssynergia should be suspected if at least two of the following are present: inability to contract abdominal muscles, inability to relax anal sphincter and/or puborectalis, paradoxical contraction of the anal sphincter or puborectalis, or absence of perineal descent ${ }^{6}$. Abnormal lesions and strictures should be noted and alternatives to manometry considered ${ }^{7}$. Any tenderness, presence of stool in the rectum, and any blood are noted. Tenderness or blood warrants a physician evaluation. In certain painful anorectal disorders such as thrombosed hemorrhoids and anorectal inflammation, ARM should be postponed until the acute process has subsided. If the rectal vault is loaded with stool, a tap water enema is administered.

Anatomical abnormalities such as strictures, uncooperative subject, and lack of informed consent are contraindications to the procedure $^{8}$.

\section{PERFORMING ARM}

\section{ARM procedure}

Manometry catheters should be calibrated before each use following manufacturer recommendation. Failure to do so may cause poor quality recording. It is important that the motility laboratory uses the same standard protocol for each subject. 
After lubrication, the probe is gently introduced into the anorectum until all the sensors are inside the body and appropriately oriented. Simultaneously, the topographic or waveform images are inspected to ensure that the probe is correctly placed and taped into position. The traces are allowed to stabilize for a period of $5 \mathrm{~min}$ before starting the maneuvers. It is important to ensure that the entire probe is inserted such that a thin sleeve of atmospheric pressure is also seen and that the rectal sensor is not kinked. During stabilization, anal ultraslow waves at 1.5-3 cycles/min can be detected. These waves may be seen in normal people as a reflection of the slow-twitch internal anal sphincter (IAS) ${ }^{9}$, but have also been described in dyschezia and anorectal pain syndrome ${ }^{10}$.

Aspects of manometry such as rectal sensory testing vary per laboratory and depend on the type, shape, length, and elasticity of the rectal balloon ${ }^{11}$. Normative data either obtained from within the laboratory or published by centers of excellence may be used ${ }^{4}$. If using values from another laboratory, it is important to follow the same protocol for performing the study.

\section{SQUEEZE PRESSURES}

The subject is instructed to squeeze their anal muscles and to hold the squeeze for as long as possible to a maximum of $30 \mathrm{~s}$. This maneuver is performed twice, with a rest interval of $1 \mathrm{~min}$ between each squeeze. If the subject has difficulty in performing the maneuver or if the pressures are low, they are advised to imagine a situation, wherein they are forcefully trying to stop and control an urgent desire to defecate (DD).

\section{Push or bearing down}

The subject is then instructed to push and bear down as if to defecate for $30 \mathrm{~s}$, on two separate occasions, with a 1-min rest interval between each maneuver.

\section{Party balloon inflation or cough reflex}

Next, the subject is given a party balloon and asked to inflate it by blowing through the mouth for 5-10 s. The maneuver is performed twice, with a $30 \mathrm{~s}$ rest interval. Alternatively, the subject is asked to cough once and repeated after a $30 \mathrm{~s}$ interval.

\section{Rectal sensation and rectoanal reflexes}

Before this test, the subject is given a rectal sensation chart that describes the possible sensations they may experience (Table 1). The subject is encouraged to report each sensation they feel. Care should be taken to ensure that the subject is unaware of the timing, duration, and volumes used for rectal distension. By inflating the rectal balloon intermittently, the following are elicited simultaneously: the rectal sensation, the rectoanal inhibitory reflex (RAIR), and the external sphincter contractile reflex.

The test starts with a volume of $10 \mathrm{~mL}$. The balloon is inflated in increments of $10 \mathrm{~mL}$ until the first sensation is reported or up to $60 \mathrm{~mL}$. 
TABLE 1. Systematic analysis and interpretation of anorectal manometry.

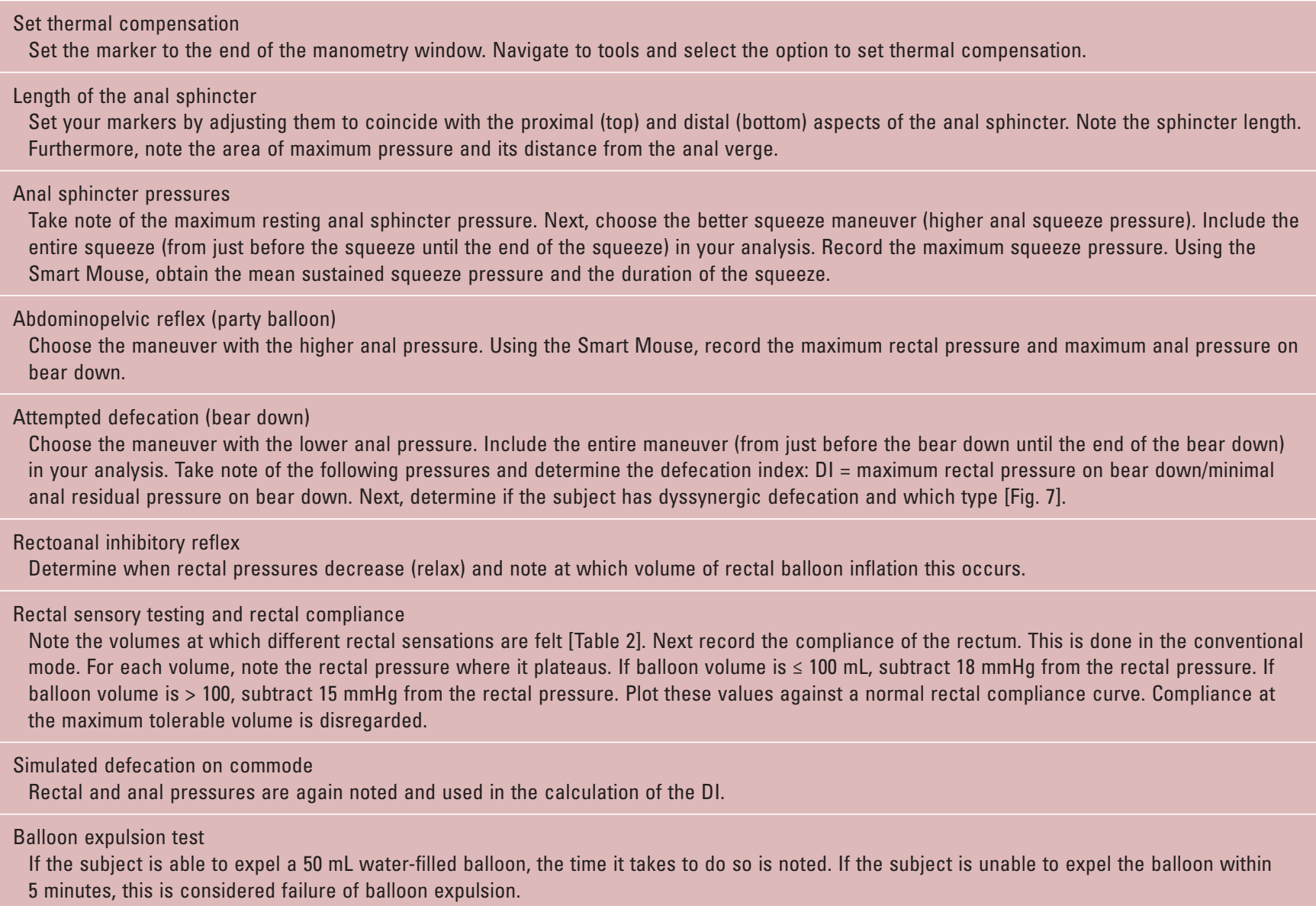

Thereafter, the balloon is inflated in steps of $30 \mathrm{~mL}$ to a maximum inflation of $320 \mathrm{~mL}$, or until maximum tolerable volume is reached.

The rate of inflation is set at $10 \mathrm{~mL} / \mathrm{s}$ to avoid dramatic changes in values. Once the balloon is distended, the inflation is maintained for $30 \mathrm{~s}$. The balloon is then deflated, and after a rest period of $30 \mathrm{~s}$, reinflated to the next volume.

During inflation, the volumes which evoke the following sensations are noted: the first transient sensation, the first constant sensation (i.e., a sensation of fullness which persists for $>20$ s; sensory threshold), desire to defecate (DD) after $15 \mathrm{~s}$ of inflation, urgent desire to defecate (DD++) after $15 \mathrm{~s}$ of inflation, and the maximum tolerable volume. The maximum volume of air that may be infused in a subject will depend on their tolerance. Hence, if the subject is unable to tolerate the distension, or experiences pain, the test is terminated at a lower volume.

\section{Push maneuver on the commode with $60 \mathrm{~mL}$ air}

To simulate more physiologic position of defecation, the subject is asked to sit on a commode with the ARM catheter in place. 
TABLE 2. Rectal sensation chart.

\begin{tabular}{|l|l|}
\hline Sensation & Definition \\
\hline First sensation & Transient sensation of fullness, bloating, or gas that disappears completely \\
\hline Constant sensation & Constant sensation of fullness, bloating, or gas that persists \\
\hline Desire to defecate (DD+) & Desire to have a bowel movement lasting $\leq 15 \mathrm{~s}$ \\
\hline Urgent desire to defecate (DD++) & Urgent desire to have a bowel movement, feeling of having to stop doing everything, and rushing to the bathroom \\
\hline Maximum tolerable volume & Maximum volume that is tolerable, often associated with severe urgency and may be associated with pain \\
\hline
\end{tabular}

A container is placed under the commode to catch the balloon, the probe, and any bowel contents, if accidentally pushed out. The rectal balloon is inflated with $60 \mathrm{~mL}$ of air. The subject is then assisted to the commode. The subject is asked to bear down for $30 \mathrm{~s}$, as if trying to evacuate their bowels. Next, the subjects are placed back on the bed and the manometry probe is removed.

\section{BET}

This test is performed with the patient on the commode. A plastic probe with a balloon is placed in the rectum and filled with $50 \mathrm{~mL}$ of warm water. Before this test, the subject is instructed on how to stop the clock immediately after expelling the balloon. The stop clock is started and the examiner leaves the room for a period of $5 \mathrm{~min}$, while the subject attempts to expel the balloon in privacy. If the subject fails to expel the balloon, confirming dyssynergia, it is deflated and removed with the probe.

\section{POST-PROCEDURE ASSESSMENT}

After the procedure, the subject is informed that they may experience mild discomfort and slight bleeding for 2-3 days. The subject is advised to inform a physician if bleeding persists. The subject is also informed that the results of the procedure and recommendations will be discussed during a follow-up clinic appointment.

\section{ANALYSES AND INTERPRETATION}

Analysis of manometric readings when using the high-resolution manometry system should begin with setting thermal compensation. Following this, the lollipop markers for the proximal and distal margins of the anal sphincter and high-pressure zone (HPZ) should be set. The manometry study should then be analyzed in a systematic manner as described in Table 2.

\section{Assessment of anal sphincter pressures}

The anal HPZ (which includes the external anal sphincter [EAS], IAS, and puborectalis) and the location of maximum resting pressure from the anal verge should be noted. The resting sphincter pressure is the difference between the atmospheric pressure and the maximum anal sphincter pressure at rest. It 

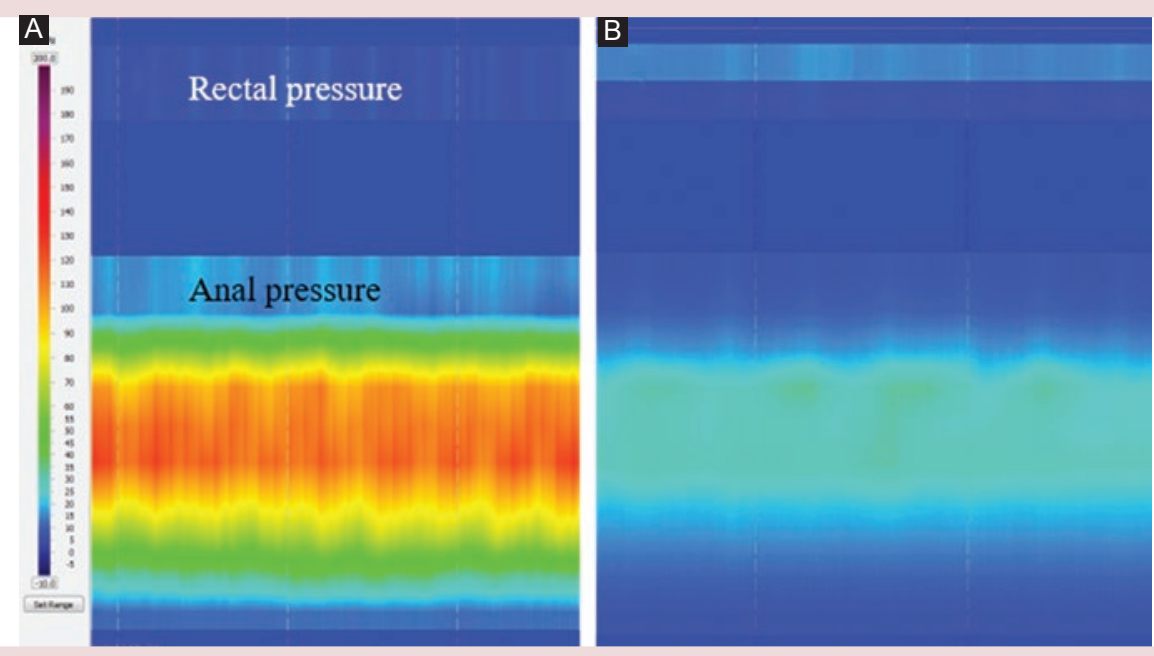

Figure 3. Manometric topography of resting anal pressure in (A) a healthy subject, and (B) a subject with fecal incontinence, showing decreased resting anal sphincter pressure in the latter.

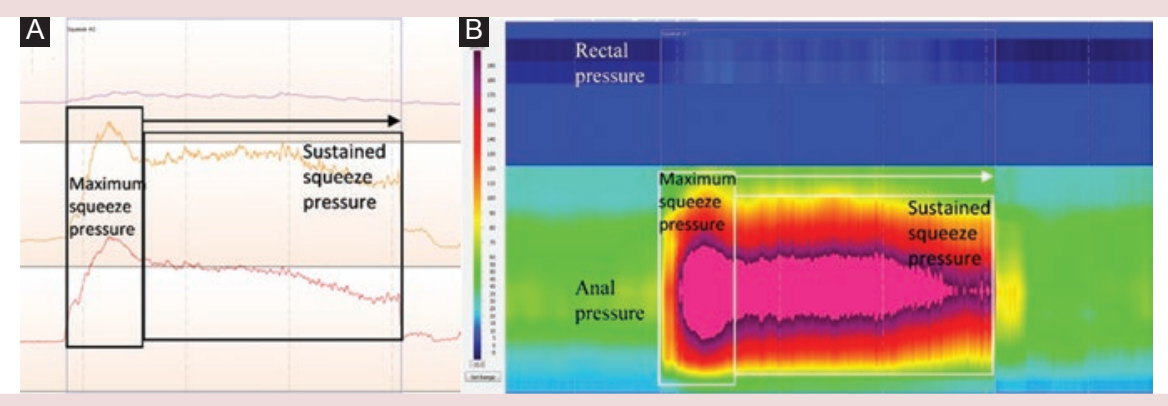

Figure 4. (A) Conventional and (B) high-resolution manometric topography of rectal and anal squeeze pressures in a healthy subject.

largely reflects the IAS pressure. Decreased resting sphincter pressure indicates weakness or defect in the IAS ${ }^{12}$ (Fig. 3).

The squeeze pressure reflects principally the strength of the EAS. The best of two attempts should be taken. The maximum squeeze pressure is the difference between atmospheric pressure and the highest recorded pressure at any level in the anal canal. The subject must be instructed and fully understand the maneuver such that the intra-abdominal pressure is not simultaneously increased. The sustained squeeze pressure is the mean pressure sustained for $>15 \mathrm{~s}$. The squeeze duration is the time during which the subject maintains a squeeze pressure at or above $50 \%$ of the maximum squeeze pressure of anal sphincters (Fig. 4). Weak squeeze pressures can indicate neuropathy or myopathy ${ }^{13}$ (Fig. 5). It 


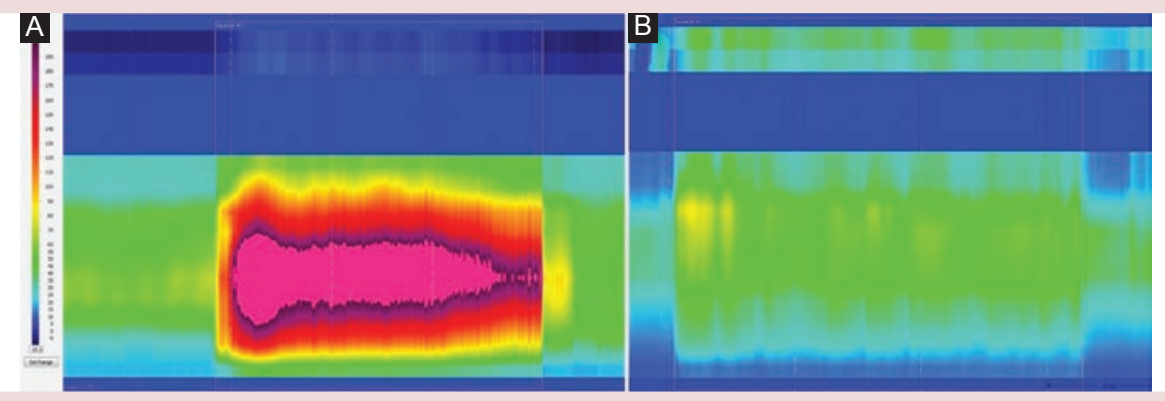

Figure 5. Manometric topography of rectal and anal squeeze pressures in (A) a healthy subject, and (B) a subject with fecal incontinence, showing decreased maximum and sustained anal sphincter pressure in the latter.

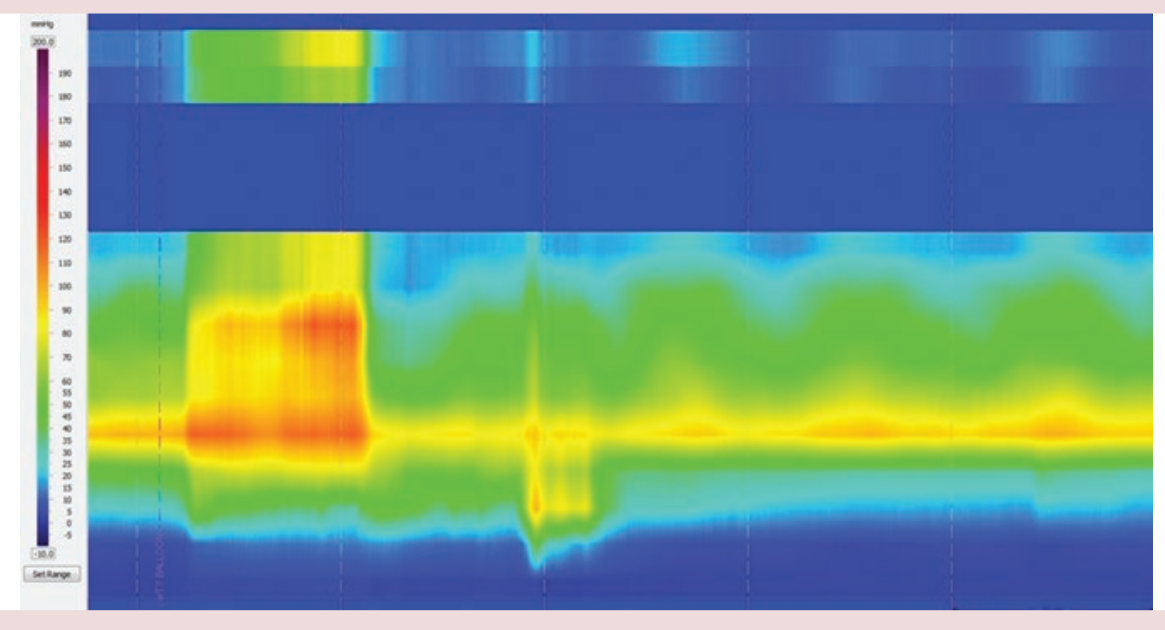

Figure 6. Manometric topography of normal abdominopelvic reflex during party balloon maneuver showing transient increase in both rectal and anal sphincter pressures.

may be possible to assess puborectalis pressures separately, if needed.

\section{Abdominopelvic reflex}

Blowing into a party balloon or a cough induces a reflex response consisting of a rapid increase in intra-abdominal pressure together with an increase in anal sphincter pressure (Fig. 6). The better of two attempts (showing higher anal pressure) is taken. The maximum pressures in the rectum and the anus are noted. In normal subjects, this local spinal reflex maintains continence during changes in intra-abdominal pressure. Abnormal results may be seen in subjects with lower motor neuron lesions such as cauda equina syndrome or sacral plexus injury. In subjects with lesions above the cauda, the reflex is present, but the squeeze response may be absent ${ }^{9}$. 

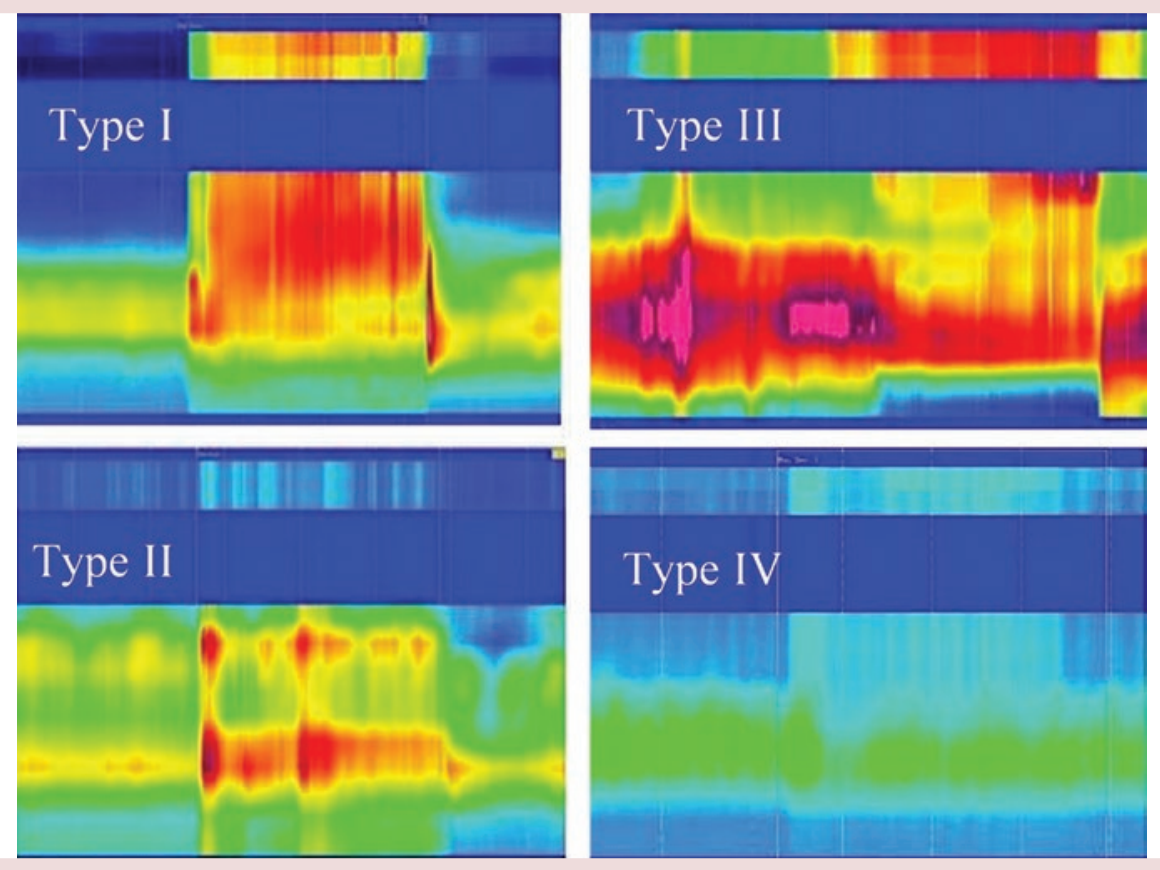

Figure 7. Manometric profiles during simulated defecation in subjects with dyssynergic defecation. In Type I dyssynergia, the subject is able to generate adequate intraabdominal pressure and push force but also generates a paradoxical increase in anal sphincter pressure. In Type II dyssynergia, the subject is unable to generate adequate pushing force and may exhibit a paradoxical increase in anal sphincter pressure. In Type II dyssynergia, the subject is unable to generate adequate pushing force with a paradoxical increase in anal sphincter pressure. In Type III dyssynergia, the subject is able to generate adequate pushing force but has absent or incomplete $(<20 \%)$ anal sphincter relaxation, with insufficient decrease in anal sphincter pressure. In Type IV dyssynergia, the subject is unable to generate adequate pushing force and has absent or incomplete anal sphincter relaxation. Figure adapted from Lee, et al., $2018^{28 .}$

\section{Push maneuver or attempted defecation}

The subject is asked to push or bear down as if to defecate while lying in the left lateral decubitus position. The best of two attempts, i.e., the maneuver that most closely resembles a normal push response, is used for measurements. The defecation index (DI) is then calculated using the formula: DI = Maximum rectal pressure on bear down/Minimal anal residual pressure on bear down. In normal subjects, bearing down creates an increase in rectal pressure and a decrease in anal sphincter pressure. Thus, the normal DI is $>$ 1.2. Inability to perform this coordinated maneuver results in dyssynergia or functional obstruction to the passage of stool. There are at least four recognized patterns of dyssynergic defecation (Fig. 7), although recent studies suggest that up to eight patterns may be seen ${ }^{14}$.

\section{RAIR}

The RAIR refers to the reflex relaxation of the IAS in response to rectal distention. It is associated with transient increase in activity of the EAS that is eliminated by higher volumes of 

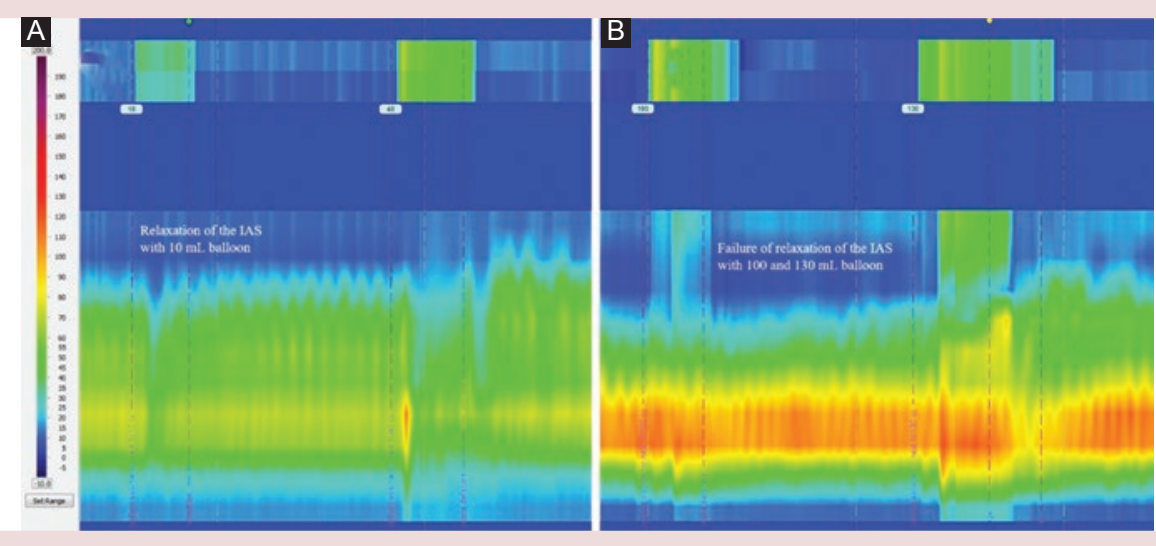

Figure 8. Manometric topography showing (A) normal rectoanal inhibitory reflex (RAIR) and (B) absent RAIR in a subject later found to have biopsy-proven Hirschsprung disease.

rectal distension ${ }^{15}$. RAIR is dependent on intact intramural autonomic ganglia, modulated by the myenteric plexus of the autonomic nervous system ${ }^{16}$, and produced by the local release of nitric oxide and vasoactive intestinal polypeptide $^{17}$. The absence of RAIR should raise suspicion for Hirschsprung's disease (Fig. 8). Idiopathic megacolon and very short aganglionoses limited to the anal canal may also cause absent RAIR ${ }^{18}$. Patients who have undergone lower anterior resection or myotomy of the anal area may have normal or abnormal RAIR ${ }^{9}$.

\section{Rectal sensory testing}

Diminished perception in at least two modalities of rectal sensation, i.e., first sensation, $\mathrm{DD}$, urgency to defecate, or maximum tolerable volume indicates rectal hyposensitivity. This is often seen in subjects with diabetes, fecal incontinence, or constipation. Two or more lower thresholds for perception indicate rectal hypersensitivity, as is seen in subjects with urge incontinence, proctitis, and irritable bowel syndrome ${ }^{19}$.

\section{Rectal compliance}

Rectal compliance is analyzed in conjunction with rectal sensation. For each volume, the rectal pressure is calculated by subtracting the intraballoon pressure from the intrarectal pressure during balloon distension. Alternatively, one may use a highly compliant rectal balloon attached to a barostat ${ }^{20}$.

Rectal compliance is the slope of the graph calculated using the formula compliance $=\mathrm{dV}$ $(\mathrm{mL}) / \mathrm{dP}(\mathrm{mmHg})$, where $\mathrm{dP}$ is the change in the intraballoon volume and $\mathrm{dP}$ is the change in the intrarectal pressure $(\mathrm{dP})$ at steady state. The curve is non-linear, and thus, plotting at least two values is useful ${ }^{21}$. It reflects the viscoelastic properties of the rectal wall and the viscoelasticity of the surrounding pelvic organs ${ }^{19}$. Decreased compliance may be seen in subjects with inflammatory bowel disease, 
chronic ischemia, history of pelvic radiation, and advancing age. Increased compliance may be seen in subjects with megarectum and sometimes in dyssynergic defecation ${ }^{20,22}$.

\section{Simulated defecation on commode}

During simulated defecation on the commode, rectal and anal sphincter pressures are again measured and used in the calculation of the $\mathrm{DI}^{23}$. The inability to coordinate the rectal push with anal relaxation is a confirmatory test for dyssynergic defecation.

\section{BET}

The BET is considered abnormal if the subject is unable to expel a $50 \mathrm{~mL}$ water-filled balloon within $1 \mathrm{~min}^{23}$. If the subject fails to expel the balloon in $1 \mathrm{~min}$, it confirms dyssynergia. Expulsion time of longer than $2 \mathrm{~min}$ is also reliable test for dyssynergia, having a higher level of agreement with ARM findings ${ }^{24}$.

\section{COMPLICATIONS OF ARM}

ARM is a generally safe and well-tolerated procedure. Complications are rare. Two iatrogenic colorectal perforations were reported, in a sample of 1501 ARM tests $(0.13 \%)$. Both subjects had a history of rectal cancer resection?

\section{CONCLUSION}

Anorectal disorders are common and often distressing to patients. Together with adjunctive tests, high-resolution ARM can confirm clinical diagnosis and provide valuable information on the underlying mechanism(s) of such disorders. Data obtained can guide therapy, such as biofeedback, to optimize management. Several studies have shown that ARM is clinically useful ${ }^{25-27}$. The studies when performed meticulously can provide invaluable information that can confirm clinical suspicion and provide a basis for rational clinical management.

\section{REFERENCES}

1. Remes-Troche JM, Rao SS. Defecation disorders: neuromuscular aspects and treatment. Curr Gastroenterol Rep. 2006;8:291-9.

2. Rao SS, Bharucha AE, Chiarioni G, et al. Anorectal disorders. Gastroenterology. 2016;150:1430-42.

3. Rao SS, Coss-Adame E, Tantiphlachiva K, Attaluri A, Remes-Troche J. Translumbar and transsacral magnetic neurostimulation for the assessment of neuropathy in fecal incontinence. Dis Colon Rectum. 2014;57:645-52.

4. Lee $\mathrm{TH}$, Bharucha AE. How to perform and interpret a high-resolution anorectal manometry test. J Neurogastroenterol Motil. 2016;22:46-59.

5. Lee YY, Erdogan A, Rao SS. High resolution and high definition anorectal manometry and pressure topography: diagnostic advance or a new kid on the block? Curr Gastroenterol Rep. 2013;15:360.

6. Rao SS. Rectal exam: yes, it can and should be done in a busy practice! Am J Gastroenterol. 2018;113:635-8.

7. Park JS, Kang SB, Kim DW, et al. Iatrogenic colorectal perforation induced by anorectal manometry: report of two cases after restorative proctectomy for distal rectal cancer. World J Gastroenterol. 2007;13:6112-4.

8. Tantiphlachiva K, Rao SS. Anorectal manometry. In: Parkman HP, McCallum RW, Rao SS, editors. GI Motility Testing: a Laboratory and Office Handbook. Thorofare: SLACK; 2011.

9. Remes-Troche JM, Rao SS. Neurophysiological testing in anorectal disorders. Expert Rev Gastroenterol Hepatol. 2008;2:323-35.

10. Eckardt VF, Schmitt T, Bernhard G. Anal ultra slow waves: a smooth muscle phenomenon associated with dyschezia. Dig Dis Sci. 1997;42:2439-45.

11. Barnett JL, Hasler WL, Camilleri M. American gastroenterological association medical position statement on anorectal testing techniques. American gastroenterological association. Gastroenterology. 1999;116:732-60.

12. Papaconstantinou HT. Evaluation of anal incontinence: minimal approach, maximal effectiveness. Clin Colon Rectal Surg. 2005;18:9-16.

13. Bharucha AE. Anorectal disorders. In: Pathophysiology of the Enteric Nervous System: a Basis for Understanding Functional Diseases. Malden: Blackwell; 2004. p. 161-75.

14. Rao SS, Leelasinjaroen P, Amieva-balmori M, et al. Characterization of dyssynergia phenotypes with high resolution anorectal manometry (HRAM). Gastroenterology. 2016;150 Suppl 1:S158-9.

15. Cheeney G, Nguyen M, Valestin J, Rao SS. Topographic and manometric characterization of the recto-anal inhibitory reflex. Neurogastroenterol Motil. 2012;24:e147-54.

16. Guinet A, Jousse M, Damphousse M, et al. Modulation of the rectoanal inhibitory reflex (RAIR): qualitative and quantitative evaluation in multiple sclerosis. Int J Colorectal Dis. 2011;26:507-13.

17. Rattan S, Sarkar A, Chakder S. Nitric oxide pathway in rectoanal inhibitory reflex of opossum internal anal sphincter. Gastroenterology. 1992; 103:43-50. 
18. Zaafouri H, Mrad S, Mabrouk M, Haoues N. Hirschsprung's disease in adults: clinical and therapeutic features. Int J Surg. 2015;2:9-17.

19. Azpiroz F, Enck P, Whitehead WE. Anorectal functional testing: review of collective experience. Am J Gastroenterol. 2002;97:232-40.

20. Rao SS, Azpiroz F, Diamant N, et al. Minimum standards of anorectal manometry. Neurogastroenterol Motil. 2002;14:553-9.

21. Rao SS, Hatfield R, Soffer E, et al. Manometric tests of anorectal function in healthy adults. Am J Gastroenterol. 1999;94:773-83.

22. Coss-Adame E, Rao SS, Valestin J, Ali-Azamar A, Remes-Troche JM. Accuracy and reproducibility of high-definition anorectal manometry and pressure topography analyses in healthy subjects. Clin Gastroenterol Hepatol. 2015;13:1143-500.

23. Rao SS, Kavlock R, Rao S. Influence of body position and stool characteristics on defecation in humans. Am J Gastroenterol. 2006;101:2790-6.
24. Chiarioni G, Kim SM, Vantini I, Whitehead WE. Validation of the balloon evacuation test: reproducibility and agreement with findings from anorectal manometry and electromyography. Clin Gastroenterol Hepatol. 2014;12:2049-54.

25. Rao SS, Patel RS. How useful are manometric tests of anorectal function in the management of defecation disorders? Am J Gastroenterol. 1997;92:469-75

26. Rao SS, Mudipalli RS, Stessman M, Zimmerman B. Investigation of the utility of colorectal function tests and Rome II criteria in dyssynergic defecation (Anismus). Neurogastroenterol Motil. 2004;16:589-96.

27. Ratuapli SK, Bharucha AE, Noelting J, Harvey DM, Zinsmeister AR. Phenotypic identification and classification of functional defecatory disorders using high-resolution anorectal manometry. Gastroenterology. 2013;144:314-2200.

28. Lee YY, Erdogan A, Yu S, Dewitt A, Rao SS. Anorectal manometry in defecatory disorders: a comparative analysis of high-resolution pressure topography and waveform manometry. J Neurogastroenterol Motil. 2018;24:460-8. 